\section{OPEN ACCESS}

Approved by:

Frontiers Editorial Office,

Frontiers Media SA, Switzerland

*Correspondence:

Sandro La Vignera

sandrolavignera@unict.it

†These authors have contributed

equally to this work

Specialty section: This article was submitted to

Cancer Endocrinology,

a section of the journal

Frontiers in Endocrinology

Received: 31 May 2019

Accepted: 03 June 2019

Published: 19 June 2019

Citation

La Vignera S, Cannarella R, Duca Y,

Barbagallo F, Burgio G

Compagnone M, Di Cataldo A,

Calogero AE and Condorelli RA (2019)

Corrigendum: Hypogonadism and

Sexual Dysfunction in Testicular Tumor

Survivors: A Systematic Review.

Front. Endocrinol. 10:393.

doi: 10.3389/fendo.2019.00393

\title{
Corrigendum: Hypogonadism and Sexual Dysfunction in Testicular Tumor Survivors: A Systematic Review
}

\begin{abstract}
Sandro La Vignera ${ }^{1 \star}$, Rossella Cannarella ${ }^{1 \dagger}$, Ylenia Duca ${ }^{1}$, Federica Barbagallo ${ }^{1}$, Giovanni Burgio ${ }^{1}$, Michele Compagnone ${ }^{1}$, Andrea Di Cataldo ${ }^{2}$, Aldo E. Calogero ${ }^{1}$ and Rosita A. Condorelli ${ }^{1}$

${ }^{1}$ Section of Endocrinology, Department of Clinical and Experimental Medicine, University of Catania, Catania, Italy, ${ }^{2}$ Unit of Pediatric Hematology and Oncology, Department of Clinical and Experimental Medicine, University of Catania, Catania, Italy

Keywords: hypogonadism, testicular tumor, testosterone, sexual dysfunction, cardiovascular risk
\end{abstract}

\section{A Corrigendum on}

Hypogonadism and Sexual Dysfunction in Testicular Tumor Survivors: A Systematic Review by La Vignera, S., Cannarella, R., Duca, Y., Barbagallo, F., Burgio, G., Compagnone, M., et al. (2019). Front. Endocrinol. 10:264. doi: 10.3389/fendo.2019.00264

An author name was incorrectly spelled as Andrea Di (first name) Cataldo (last name). The correct spelling is Andrea (first name) Di Cataldo (last name). The authors apologize for this error and state that this does not change the scientific conclusions of the article in any way. The original article has been updated.

Copyright () 2019 La Vignera, Cannarella, Duca, Barbagallo, Burgio, Compagnone, Di Cataldo, Calogero and Condorelli. This is an open-access article distributed under the terms of the Creative Commons Attribution License (CC BY). The use, distribution or reproduction in other forums is permitted, provided the original author(s) and the copyright owner(s) are credited and that the original publication in this journal is cited, in accordance with accepted academic practice. No use, distribution or reproduction is permitted which does not comply with these terms. 